Leading Our World In Motion

SAE TECHNICAL

PAPER SERIES

\title{
Design Under Uncertainty and Assessment of Performance Reliability of a Dual-Use Medium Truck with Hydraulic-Hybrid Powertrain and Fuel Cell Auxiliary Power Unit
}

\author{
Michael Kokkolaras ${ }^{1}$, Zissimos Mourelatos ${ }^{2}$, Loucas Louca ${ }^{3}$, \\ Zoran Filipi ${ }^{1}$, George Delagrammatikas ${ }^{4}$, Anna Stefanopoulou ${ }^{1}$, \\ Panos Papalambros ${ }^{1}$, and Dennis Assanis ${ }^{1}$ \\ ${ }^{1}$ University of Michigan, Ann Arbor \\ ${ }^{2}$ Oakland University, Rochester \\ ${ }^{3}$ University of Cyprus, Nicosia, Cyprus \\ ${ }^{4}$ California Polytechnic State University, San Luis Obispo
}

Reprinted From: Reliability and Robust Design in Automotive Engineering 2005

(SP-1956)

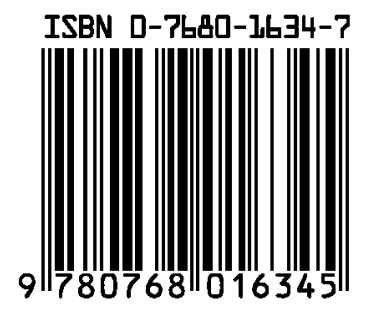


The Engineering Meetings Board has approved this paper for publication. It has successfully completed SAE's peer review process under the supervision of the session organizer. This process requires a minimum of three (3) reviews by industry experts.

All rights reserved. No part of this publication may be reproduced, stored in a retrieval system, or transmitted, in any form or by any means, electronic, mechanical, photocopying, recording, or otherwise, without the prior written permission of SAE.

For permission and licensing requests contact:

SAE Permissions
400 Commonwealth Drive
Warrendale, PA 15096-0001-USA
Email: permissions@ @ae.org
Tel: $724-772-4028$
Fax: $\quad 724-772-4891$

Fax: $\quad 724-772-4891$

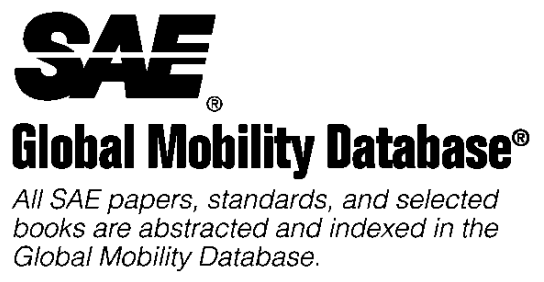

For multiple print copies contact:

SAE Customer Service

Tel: $\quad$ 877-606-7323 (inside USA and Canada)

Tel: $\quad$ 724-776-4970 (outside USA)

Fax: $\quad$ 724-776-1615

Email: CustomerService@sae.org

\section{ISSN 0148-7191}

\section{Copyright $\odot 2005$ SAE International}

Positions and opinions advanced in this paper are those of the author(s) and not necessarily those of SAE. The author is solely responsible for the content of the paper. A process is available by which discussions will be printed with the paper if it is published in SAE Transactions.

Persons wishing to submit papers to be considered for presentation or publication by SAE should send the manuscript or a 300 word abstract to Secretary, Engineering Meetings Board, SAE.

\section{Printed in USA}




\title{
Design Under Uncertainty and Assessment of Performance Reliability of a Dual-Use Medium Truck with Hydraulic-Hybrid Powertrain and Fuel Cell Auxiliary Power Unit
}

\author{
Michael Kokkolaras ${ }^{1}$, Zissimos Mourelatos ${ }^{2}$, Loucas Louca ${ }^{3}$, Zoran Filipi', \\ George Delagrammatikas ${ }^{4}$, Anna Stefanopoulou', Panos Papalambros ${ }^{1}$, Dennis Assanis ${ }^{1}$ \\ ${ }^{1}$ University of Michigan, Ann Arbor \\ ${ }^{2}$ Oakland University, Rochester \\ ${ }^{3}$ University of Cyprus, Nicosia, Cyprus \\ ${ }^{4}$ California Polytechnic State University, San Luis Obispo
}

Copyright @ 2005 SAE International

\begin{abstract}
Medium trucks constitute a large market segment of the commercial transportation sector, and are also used widely for military tactical operations. Recent technological advances in hybrid powertrains and fuel cell auxiliary power units have enabled design alternatives that can improve fuel economy and reduce emissions dramatically. However, deterministic design optimization of these configurations may yield designs that are optimal with respect to performance but raise concerns regarding the reliability of achieving that performance over lifetime. In this article we identify and quantify uncertainties due to modeling approximations or incomplete information. We then model their propagation using Monte Carlo simulation and perform sensitivity analysis to isolate statistically significant uncertainties. Finally, we formulate and solve a series of reliabilitybased optimization problems and quantify tradeoffs between optimality and reliability. The most relevant design parameters of the diesel engine, fuel cell, driveline and vehicle are considered. The results demonstrate the necessity for addressing uncertainty to make valid assessments and design decisions.
\end{abstract}

\section{INTRODUCTION}

Improving the fuel efficiency of medium-sized trucks (Class 6) has significant dual-use implications, as increasing fuel prices strain both the commercial transportation industry and military logistics support.

Fuel is not only consumed while the trucks are being driven, but also when they stand still. Traditional configurations use the diesel engine to supply the energy needed for climate control and cabin accessories and/or performing utility-truck tasks in the commercial sector, and surveillance and communication tasks in the military sector. This is a poor strategy because the engine is operating under highly inefficient conditions, i.e., low speed and load. In addition, it is environmentally detrimental due to the increased emissions. Lastly, it is a source of noise, which is especially undesirable for military operations.

Recent efforts for improving fuel efficiency of medium trucks have focused on hybridizing the powertrain. Previous simulation studies of coordinated power management and optimal design have shown that hybrid-hydraulic configurations yield higher fuel economy benefits relative to electric-hybrid configurations, particularly for highly-transient duty cycles. Fuel economy improvements of up to $47 \%$ were reported for a delivery truck [1], and $32 \%$ for a larger $6 \times 6$ off-road medium tactical truck [2]. The advantages of the hydraulic hybrid option were attributed mostly to their superior efficiency in energy regeneration and storage. Nevertheless, there is an increasing need for on-board electric energy in both commercial and military trucks in order to supply the required power for electric accessories used during the so-called "silent-watch". To eliminate the need for excessive near-idle engine operation and overcome the energy density and capacity disadvantages of batteries, while fully exploiting the benefits of the hybrid-hydraulic configurations, fuel cells (FC) are considered as auxiliary power units (APUs) enabling electrification of powertrain components [3-7]. A recent simulation-based analysis demonstrated that using a fuel cell APU can improve fuel economy up to $10 \%$ while driving and almost six times while at standstill, during the silent watch (relative to using a diesel engine only) [8]. The benefits of electrifying the accessories and powering them with the FC APU during driving are over-and-above the improvements resulting from hybridization. 
The aforementioned encouraging results were obtained by optimizing a selected set of vehicle system level design parameters (engine size, hydraulic pump-motor size and gear ratio, and accumulator parameters), and without considering details of engine-design. In addition, the optimization and consequent evaluation of the fuel economy potential of a particular technology was performed in a deterministic manner, without considering possible uncertainties in design and operating parameters, hence the motivation for further work. In the first part of this article, we use high-fidelity tools for simulating the diesel engine, driveline and vehicle dynamics, to design the engine and the rest of the powertrain components for optimal vehicle performance. This is done without taking into account the reliability of the obtained design, the uncertainties inherent to the engine, fuel cell, and vehicle modeling processes, and the sensitivity with respect to parameters related to emerging technologies. Subsequently, the second part of the article is concerned with quantifying and propagating uncertainties of engine, fuel cell, driveline and vehicle parameters and analyzing their implications on design and reliability of performance.

The paper is organized as follows. In the following section we formulate the optimal design problem for a medium-sized truck and describe briefly the simulation models used for evaluating design alternatives. In the next section we identify and quantify sources of uncertainty in the modeling process, and determine the most important ones by means of a cumulative distribution function sensitivity analysis technique. We then perform a parametric, probabilistic optimization study to quantify performance reliability tradeoffs. We finally summarize our findings and draw conclusions.

\section{OPTIMAL HYDRAULIC-HYBRID POWERTRAIN DESIGN FOR A DUAL-USE MEDIUM TRUCK}

We consider the following optimal design problem:

maximize fuel economy

\section{with respect to powertrain design variables}

\section{subject to performance constraints}

Full vehicle simulation is used to evaluate fuel economy and three performance constraints (acceleration time from 0 to $45 \mathrm{mph}$ should not exceed 24 seconds, and the truck should be able to maintain a maximum speed of $55 \mathrm{mph}$ and $45 \mathrm{mph}$ on $2 \%$ and $3 \%$ grade, respectively). It must be emphasized, since it affects the design significantly, that all constraints are evaluated assuming that only the engine is used for propulsion. This is according to military survivability and mobility requirements.

The considered dual-use truck is based on the configuration of a medium tactical (military) vehicle with a gross vehicle weight of $15,300 \mathrm{~kg}$. It is a $6 \times 6$, full time all-wheel-drive truck, powered by a $246 \mathrm{~kW}$ six-cylinder, turbocharged, intercooled, direct injection diesel engine.
The truck is modeled using the high-fidelity VehicleEngine-SIMulation (VESIM) environment developed at the Automotive Research Center at the University of Michigan, which has been validated and used extensively [9-11]. A detailed description of the VESIM model used in this work is given in [2, 8]. It includes the embedded hydraulic system consisting of a pump/motor, a transfer case, a reservoir, and an accumulator [2].

The same driving cycle as in [8] has been used to evaluate fuel economy, and is depicted in Figure 1. The total simulation real-time amounts to 2200 seconds, and corresponds to covering a distance of approximately 25 $\mathrm{km}$ on a network of primary, secondary, and crosscountry roads. This driving schedule is chosen to represent both commercial and military scenarios.
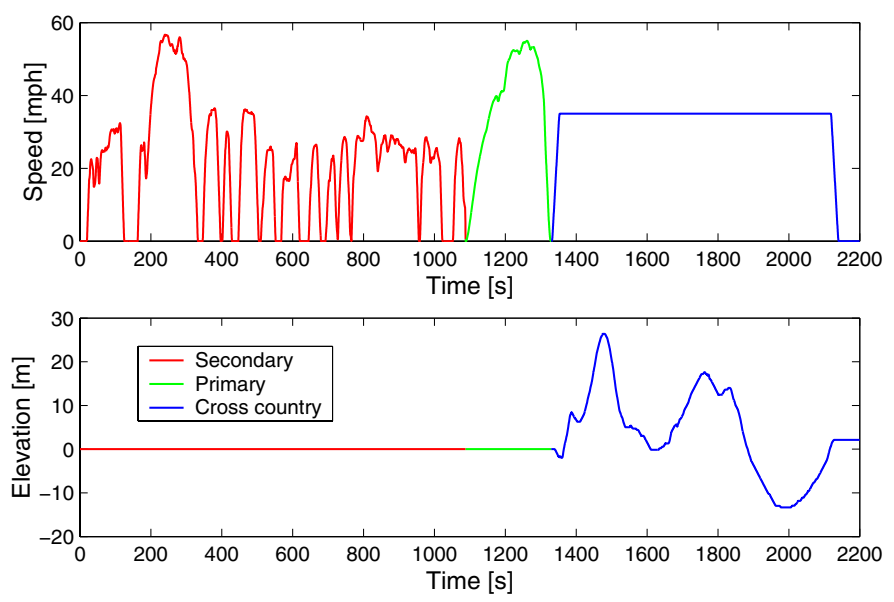

Figure 1: Driving cycle

The fuel cell APU in the proposed truck design configuration is not only used to supply power for the silent-watch tasks when the truck is at rest, but also to electrify the following engine accessories: oil pump, power steering pump, and air compressor. We use the same load-distribution of these accessories over the driving cycle as presented in [8].

The high-fidelity Turbocharged Diesel Engine Simulation (TDES) tool was used to model the diesel engine [1214]. The user provides the TDES code with over fifty inputs characterizing the engine's geometry, operation, and empirical correlation parameters, which are applied to the diesel four-stroke cycle using fundamental first principles. A quasi-static, zero-dimensional treatment of intake, compression, combustion, and exhaust yields cycle-averaged (e.g., brake specific fuel consumption, torque, and power) and time-resolved quantities (e.g., incylinder pressures, temperatures, and heat release rates) for a single, steady-state operating point. TDES automatically generates the engine's maximum torque curve and a complete torque map. Bore, stroke, connecting rod length, valve and port diameters, and valve lift profiles are adjusted through an automated scaling routine which includes knowledge of the compression ratio. Boost pressure and wastegate 
activation speed are used in an engine boosting parameterization scheme. This method has decreased computational time and increased robustness by supplying TDES with appropriate intake and exhaust manifold pressures throughout its entire operating range. By defining turbine and compressor efficiencies, predictive accuracy remains uncompromised throughout the torque map without the need for turbomachinery maps.

Eight design variables were chosen to represent the diesel engine and the hydraulic system: engine displacement and compression ratio, boost pressure, wastegate activation speed, pump size (equal to motor size), first gear ratio, and accumulator displacement and compression ratio. The optimization strategy consisted of using the derivative-free algorithm Dlvided RECTangles (DIRECT) [15] to explore the design space defined by the variable bounds as much as possible, increasing the probability of finding a global optimum, and then the Matlab implementation of the Sequential Quadratic Programming (SQP) algorithm [16] to converge to a local optimum efficiently.

The design variables, their lower and upper bounds, and their baseline and optimal values are listed in Table 1. It can be seen that the optimal values of 6 of the 8 design variables are at their lower or upper bound.

Table 1: Design variables, bounds, baseline, and optimal values (subscript and superscript stars denote lower and upper bound value, respectively)

\begin{tabular}{|l|c|c|c|c|}
\hline \multicolumn{1}{|c|}{ Design variable } & $\begin{array}{c}\text { Lower } \\
\text { bound }\end{array}$ & $\begin{array}{c}\text { Upper } \\
\text { bound }\end{array}$ & $\begin{array}{c}\text { Baseline } \\
\text { value }\end{array}$ & $\begin{array}{c}\text { Optimal } \\
\text { value }\end{array}$ \\
\hline $\begin{array}{l}\text { Engine displacement } \\
\text { [L] }\end{array}$ & 6.0 & 9.0 & 7.2 & $6.0^{*}$ \\
\hline $\begin{array}{l}\text { Engine compression } \\
\text { ratio [-] }\end{array}$ & 12 & 20 & 16 & $20^{*}$ \\
\hline Boost pressure [bar] & 1.8 & 3.0 & 2.0 & $3.0^{*}$ \\
\hline $\begin{array}{l}\text { Waste activation } \\
\text { speed [RPM] }\end{array}$ & 1000 & 1600 & 1000 & $1000^{*}$ \\
\hline Pump/motor size [L] & 0.125 & 0.50 & 0.38 & $0.50^{*}$ \\
\hline $1^{\text {st }}$ gear ratio [-] & 1.5 & 3.0 & 2.2 & 2.3 \\
\hline Accumulator size [L] & 80 & 130 & 100 & $130 *$ \\
\hline $\begin{array}{l}\text { Accumulator } \\
\text { compression ratio [-] }\end{array}$ & 2.0 & 2.8 & 2.5 & 2.55 \\
\hline
\end{tabular}

This optimal powertrain design yields an improvement of $10.76 \%$ in fuel economy relative to the baseline; performance constraints are not active. This means that the design is solely restricted by the choice of bound values on the design variables. For example, consider the two-dimensional plane cut of the eight-dimensional design space as depicted in Figure 2. With the variable bound values on engine displacement and compression ratio from Table 1, the optimum ("optimum 1") is at the intersection of the bound constraints (note the fuel economy contours). The acceleration constraint is not active, i.e., the optimum is not on the constraint boundary but in the interior of the feasible constraint domain. If we decrease the compression ratio upper bound value to 17 , then the acceleration constraint becomes active, but the engine displacement optimal value is still $6 \mathrm{~L}$ ("optimum 2"). If we further wish to decrease the upper bound value of the compression ratio to 15 , then the engine size needs to be increased to $6.6 \mathrm{~L}$ to satisfy the (active) constraint ("optimum 3"). Note that fuel economy is deteriorated in this boundmoving process.

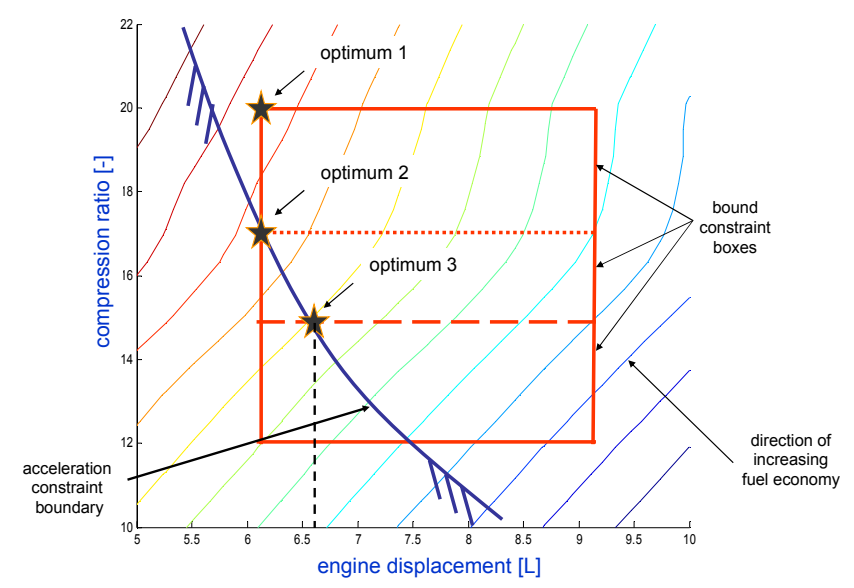

Figure 2: Activity of bound and performance constraints

The above observations have some interesting implications. Note that the engine design of Table 1 entails maximal compression ratio and boost pressure that is activated at minimal engine speed. This enables downsizing the engine as much as possible (minimal size) to improve fuel economy. Such a design is not unrealistic, but it does raise concerns regarding its lifecycle reliability and materials fatigue. If we decrease the upper bound values for variables such as compression ratio and boost pressure, we obtain designs that are associated with active performance constraints. In this situation, however, we have to ask the question of whether any design realization, life-cycle, and other uncertainties impact the reliability of satisfying these constraints, since small deviations from nominal values of design variables and/or parameters can cause violation of constraints.

\section{IMPACT OF UNCERTAINTIES}

There are many sources of uncertainty that can affect the performance of the truck during its lifetime. First there are modeling uncertainties in the simulation process due to approximations, lack of data, and incomplete knowledge when dealing with advanced but 
relatively immature technologies. Then there are uncertainties related to the realization of the design, i.e., the manufacturing process. Finally, there are uncertainties related to the operating conditions of the truck, e.g., weather, geographical profile, mission characteristics, etc. In this work we focus on analyzing uncertainties related to modeling and simulations. Figure 3 illustrates the propagation of uncertainties through the high fidelity tools used in the simulations.

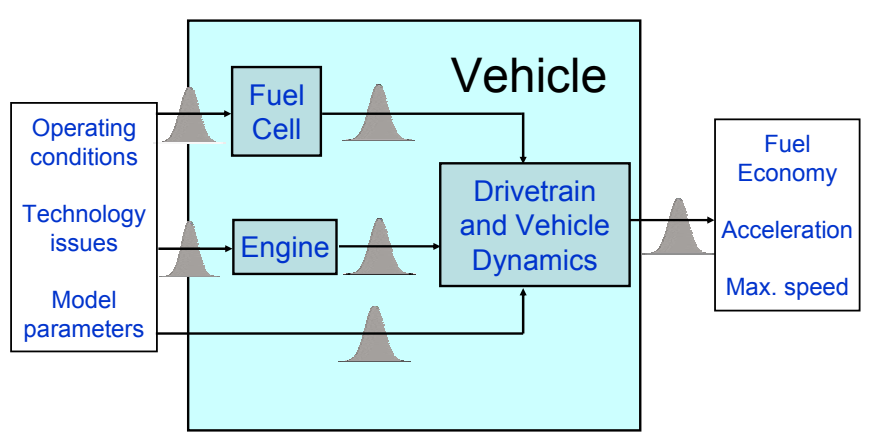

Figure 3: Propagation of uncertainties in the simulation

\section{FUEL CELL UNCERTAINTIES}

The fuel cell system employed here is described in detail in [8]. It is sized to power load all the demands during silent watch and electrify the diesel engine auxiliary. The loads during silent watch include the power supply for ventilation, nuclear-biological-chemical (NBC) protection, air-conditioning, communication, and navigation. The combined silent watch and mild diesel electrification tasks required a $10 \mathrm{~kW}$ fuel cell stack. The power specifications were met with a stack of 65 cells with 300 $\mathrm{cm}^{2}$ active membrane electrode assembly (MEA) area. The fuel cell is fed by a diesel-fuel reformer through catalytic partial oxidation.

The fuel cell performance depends on three operating variables. Namely, temperature, membrane humidity, and oxygen excess ratio. From these three factors, temperature and membrane humidity exhibit large variation within a single cell and from cell to cell. Ideal values are around $65{ }^{\circ} \mathrm{C}$ and 14 , respectively, but in reality the fuel cell can be operating in a wider range. We model these two uncertain quantities as random parameters with beta distributions that are skewed towards the right end of the interval. In addition to the operating variables, membrane thickness poses an additional and quite interesting type of uncertainty for the fuel cell performance due to its direct impact to the ionic cell resistance and the diffusion coefficient. Increasing the membrane thickness improves reliability but it decreases cell efficiency and water diffusion through the membrane followed by anode drying conditions. Fuel cell designers have not reached a consensus yet whether thinner or thicker membranes should be used. Therefore, it is important to consider a wide range of possibilities during the evolution of the system. We model this uncertainty using a random parameter with a uniform distribution. Table 2 summarizes the distribution types and parameters of the fuel cell uncertain quantities. The four beta distribution parameters represent lower and upper range limits and function shape parameters. The two uniform distribution parameters represent lower and upper range limits.

Table 2: Fuel cell random parameters

\begin{tabular}{|l|c|}
\hline \multicolumn{1}{|c|}{ Random parameter } & Distribution information \\
\hline Temperature $\left[{ }^{\circ} \mathrm{C}\right]$ & $\operatorname{Beta}(50,65,6,2)$ \\
\hline Humidity ratio $[-]$ & $\operatorname{Beta}(5,14,6,2)$ \\
\hline Membrane thickness $[\mathrm{cm}]$ & Uniform $(0.0125,0.0175)$ \\
\hline
\end{tabular}

A set of experimental data from a similar 24 cell stack was used to quantify the cell-cell variability. Furthermore, to estimate the impact of uncertain operating conditions on the output of interest of the fuel cell system, i.e., the delivered voltage, we performed 1,000 Monte Carlo simulations by sampling values for the random parameters according to the distributions of Table 2. The simulations were performed on a detailed model of the stack polarization curve found in [17].

The results are shown in Figure 4. It can be observed that there is a variation of $+/-10-50 \%$ depending on the load, i.e., the current output demanded. Using the generated polarization curves, we simulated 1,000 silent watches and obtained an estimate of the probability density function for the fuel consumption depicted in Figure 5, which demonstrates the adverse effects of the uncertainties on efficiency (note that the outliers are biased towards high fuel consumption).

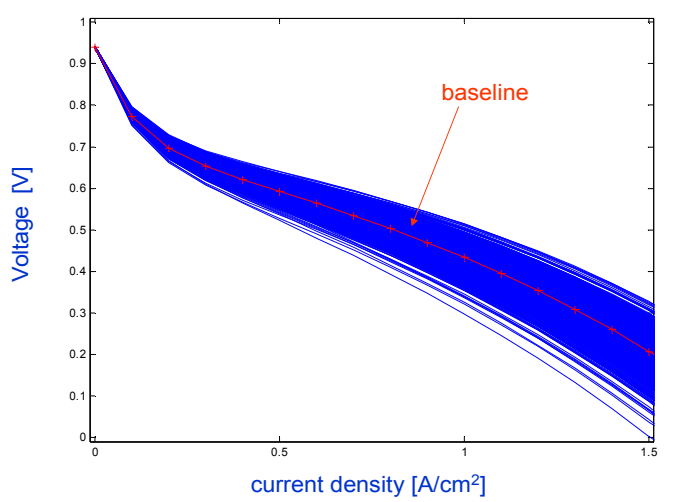

Figure 4: Polarization curves generated using Monte Carlo simulation (1,000 samples) 


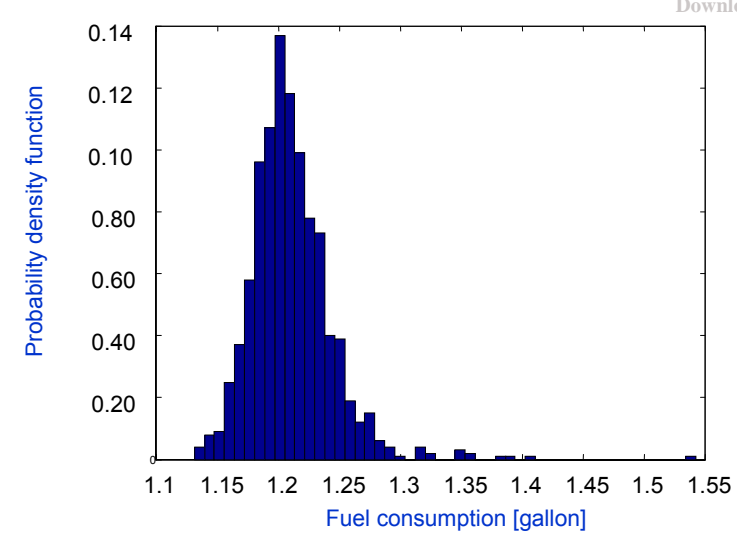

Figure 5: Estimated PDF of the silent watch fuel consumption using the fuel cell

\section{ENGINE SIMULATION UNCERTAINTIES}

The Turbocharged Diesel Engine Simulation tool used to generate the torque maps fed into VESIM for the vehicle simulation takes as inputs a large number of parameters. In the optimization study presented in the previous section, these parameters were assigned constant values. In reality however, several parameters are uncertain, and can take values within a range according to a distribution dictated by knowledge or data. In fact, the engine design variables (first 4 variables in Table 1) were also considered to be random since exact displacement cannot be realized due to manufacturing imperfections, and compression ratio, boost pressure, and wastegate activation speed optimal values cannot be achieved with high accuracy. The distribution types and parameters of the engine random quantities are listed in Table 3. The normal distribution parameters represent mean and standard deviation.

Table 3: Engine random parameters

\begin{tabular}{|l|c|}
\hline \multicolumn{1}{|c|}{ Random parameter } & Distribution information \\
\hline Displacement [L] & $\mathrm{N}(7.2,0.036)$ \\
\hline Compression ratio [-] & $\mathrm{N}(16,0.25)$ \\
\hline Boost pressure [bar] & Uniform $(1.8,2.2)$ \\
\hline Wastegate activation speed [RPM] & Uniform $(850,1150)$ \\
\hline Injection timing [ ${ }^{\circ}$ ATDC] & Uniform $(348,352)$ \\
\hline Ambient temperature [ $\left.{ }^{0} \mathrm{~K}\right]$ & Uniform $(273,320)$ \\
\hline $\begin{array}{l}\text { Heat radiation coefficient [-] (heat } \\
\text { transfer modeling) }\end{array}$ & Uniform $(1.95,2.05)$ \\
\hline $\begin{array}{l}\text { Heat convection coefficient [-] (heat } \\
\text { transfer modeling) }\end{array}$ & Uniform $(0.035,0.075)$ \\
\hline Heat transfer model exponent [-] & Uniform $(0.6,1)$ \\
\hline $\begin{array}{l}\text { Friction correlation model } \\
\text { coefficient A [-] }\end{array}$ & $\mathrm{N}(7,0.175)$ \\
\hline
\end{tabular}

\begin{tabular}{|l|c|}
\hline $\begin{array}{l}\text { Friction correlation model } \\
\text { coefficient B [-] }\end{array}$ & $\mathrm{N}(1.5,0.375)$ \\
\hline Isentropic compressor efficiency [-] & $\mathrm{N}(0.783,0.025)$ \\
\hline Turbine efficiency [-] & $\mathrm{N}(0.8,0.025)$ \\
\hline $\begin{array}{l}\text { Watson heat release correlation } \\
\text { coefficient A [-] }\end{array}$ & $\mathrm{N}(0.926,0.07)$ \\
\hline $\begin{array}{l}\text { Watson heat release correlation } \\
\text { coefficient B [-] }\end{array}$ & $\mathrm{N}(14.2,1.065)$ \\
\hline Combustion time [ ${ }^{\circ}$ ATDC] & $\mathrm{N}(125,5)$ \\
\hline $\begin{array}{l}\text { Fuel air equivalence ratio upper } \\
\text { bound [-] }\end{array}$ & Uniform $(0.665,0.735)$ \\
\hline $\begin{array}{l}\text { Intake valve opening timing } \\
{\left[{ }^{\circ} \text { ATDC] }\right.}\end{array}$ & $\mathrm{N}(-17,1.5)$ \\
\hline $\begin{array}{l}\text { Exhaust valve opening timing } \\
{\left[{ }^{\circ} \text { ATDC] }\right.}\end{array}$ & $\mathrm{N}(490,1.5)$ \\
\hline
\end{tabular}

Similarly to what we did for the fuel cell, we identified these parameters and performed Monte Carlo simulations to assess their impact on the results. Figure 6 illustrates the large variation of the maximal torque curve for 1000 samples (+/- $40 \%$ deviation from baseline at the peak value).

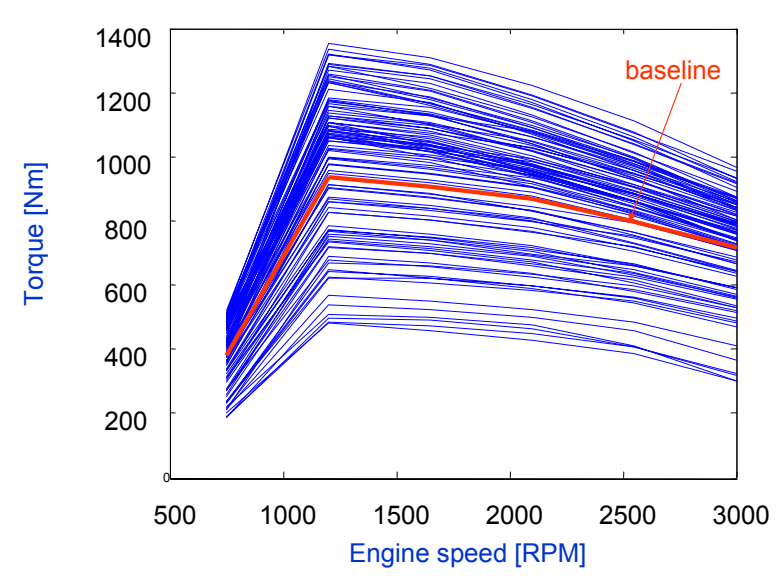

Figure 6: Torque variation due to engine modeling uncertainties

\section{VEHICLE DYNAMICS AND DRIVETRAIN MODEL UNCERTAINTIES}

Vehicle dynamics and drivetrain model uncertainties include modeling parameters that cannot be determined exactly and quantities that represent incomplete information regarding the state of the vehicle during its lifetime. For example, we can represent different tire/soil interactions (due to different road conditions and/or and badly maintained or flat tire pressures) by treating the rolling resistance parameters as random. Also, various cargo configurations result into different coefficient of 
drag and frontal areas, which can also be represented by random parameters. In addition, the efficiencies of the transmission and differentials are treated as random parameters due to lack of knowledge of exact parameter values and the variation during their lifetime. Power requirements and efficiencies of engine and vehicle accessories are also considered to be uncertain due to variations during their lifetime. Last but not least, the uncertainties propagated by the fuel cell and the diesel engine, i.e., polarization curve, maximum torque curve, and engine torque map, must also be taken into account during the full vehicle simulations. Table 4 summarizes random quantities and their distribution types and parameters.

Table 4: Vehicle simulation random parameters

\begin{tabular}{|l|c|}
\hline \multicolumn{1}{|c|}{ Random parameter } & Distribution information \\
\hline $\begin{array}{l}\text { Gear efficiency [-] (one for each } \\
\text { gear, 7-gear transmission) }\end{array}$ & Uniform(0.9,0.98) \\
\hline $\begin{array}{l}\text { Transmission ratio scaling factors } \\
\text { [-] (one for each gear, 7-gear } \\
\text { transmission) }\end{array}$ & $\mathrm{N}(1,0.1)$ \\
\hline $\begin{array}{l}\text { Differential efficiency [-] (one for } \\
\text { each of the 3 differentials) }\end{array}$ & Uniform $(0.85,0.9)$ \\
\hline $\begin{array}{l}\text { Rolling resistance scaling factors [-] } \\
\text { (one for each of the three axles) }\end{array}$ & $\mathrm{N}(1,0.1)$ \\
\hline Frontal area [m ${ }^{2}$ ] & $\mathrm{N}(7.5,0.75)$ \\
\hline Drag coefficient [-] & $\mathrm{N}(0.75,0.0375)$ \\
\hline Transmission fluid viscosity [kg/ms] & Beta(0.005,0.1,2,6) \\
\hline Pump friction losses [Nm] & $\mathrm{N}(-34,3.5)$ \\
\hline Airbrake friction losses [Nm] & $\mathrm{N}(5,1)$ \\
\hline Electrical accessories efficiency [-] & Uniform(0.85,0.92) \\
\hline $\begin{array}{l}\text { Reservoir and accumulator friction } \\
\text { losses [\%] }\end{array}$ & Uniform $(0.01,0.05)$ \\
\hline $\begin{array}{l}\text { Altitude [m] (to compute ambient } \\
\text { temperatures and pressures) }\end{array}$ & Beta(0,3000,2,6) \\
\hline Polarization curve & $\begin{array}{l}\text { As propagated from the } \\
\text { fuel cell }\end{array}$ \\
\hline $\begin{array}{l}\text { Torque map and maximal torque } \\
\text { curve }\end{array}$ & $\begin{array}{l}\text { As propagated from the } \\
\text { engine }\end{array}$ \\
\hline
\end{tabular}

The variation of the above mentioned parameters where easily implemented in VESIM since they already existed in the model. This was possible due to the modeling approach and implementation. All VESIM component models are developed based on physical quantities that are directly calculated from the geometry and material properties of the components. During the simulations and optimizations, the corresponding parameters were changed and then fed to the stand alone executable of the integrated vehicle model.
Using the fuel cell polarization curves, maximum torque curves, and engine torque maps (obtained from the previous Monte Carlo simulations), and sampling the random parameters of Table 4, 1,000 full vehicle simulations were executed to obtain fuel economy statistics of the medium truck for the driving cycle of Figure 1. The estimated PDF is depicted in Figure 7. Considering that the baseline fuel economy is $6.5 \mathrm{mpg}$, we can conclude that the impact of uncertainties is adversary in the vast majority of the cases.

\section{DESIGN OPTIMIZATION UNDER UNCERTAINTY}

Deterministic, simulation-based design optimization of engineering systems can be a computationally intensive process that may become prohibitively expensive as the number of optimization variables increases.

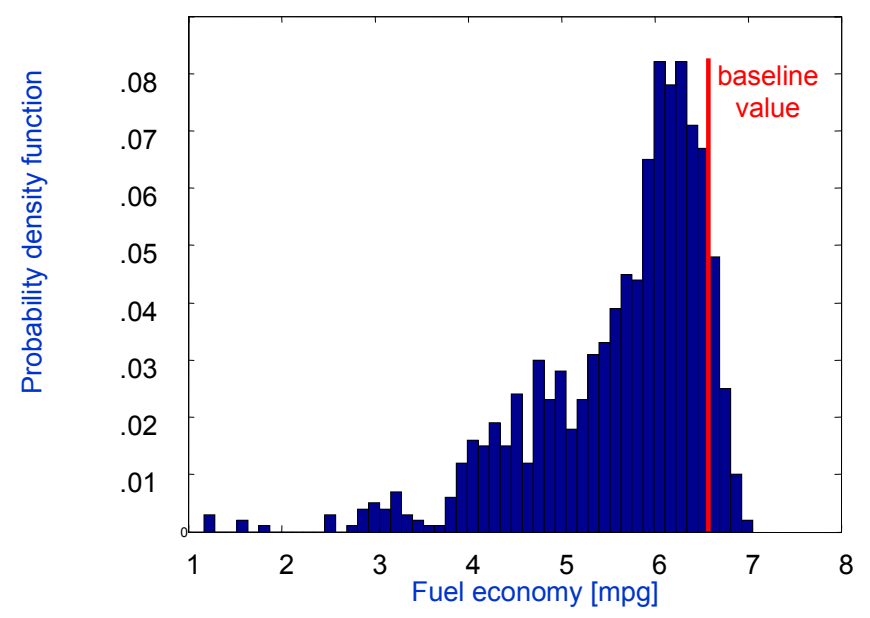

Figure 7: Estimated PDF of fuel economy

The additional computational effort required for taking into account uncertainties makes optimization under uncertainty even more computationally intensive.

The typical remedy to this problem is the creation of surrogate models that can be used in the optimization process instead of the expensive simulation models. Surrogate models are much less expensive but are less accurate. Therefore, it is important to use them appropriately for exploring the design space and to use the high-fidelity simulation tools for validating final design decisions.

The challenge of metamodeling lies in sampling the design space to generate the input-output relations used to create the surrogate models. It is impractical to consider a large number of dimensions (more than, say, 10) because the required number of input-output relations (and therefore the number of high-fidelity simulations) increases exponentially. 


\section{VARIABLE SCREENING}

The only solution available to the aforementioned dimensionality curse is to identify the most important variables and decrease the size of the problem. Having the results of the previous Monte Carlo simulations available, we used a CDF sensitivity analysis technique [18] to identify which of the random parameters in the simulations are statistically significant.

This method defines confidence intervals according to the number of available Monte Carlo simulations and computes sensitivities of the estimated CDFs of outputs with respect to the random inputs at different CDF levels. Thus, we are able to obtain global sensitivity metrics over the entire CDF range of the outputs. If the curves that fit the sensitivity data are within the confidence intervals, then the input is statistically insignificant to the output. Two examples are shown in Figure 8.
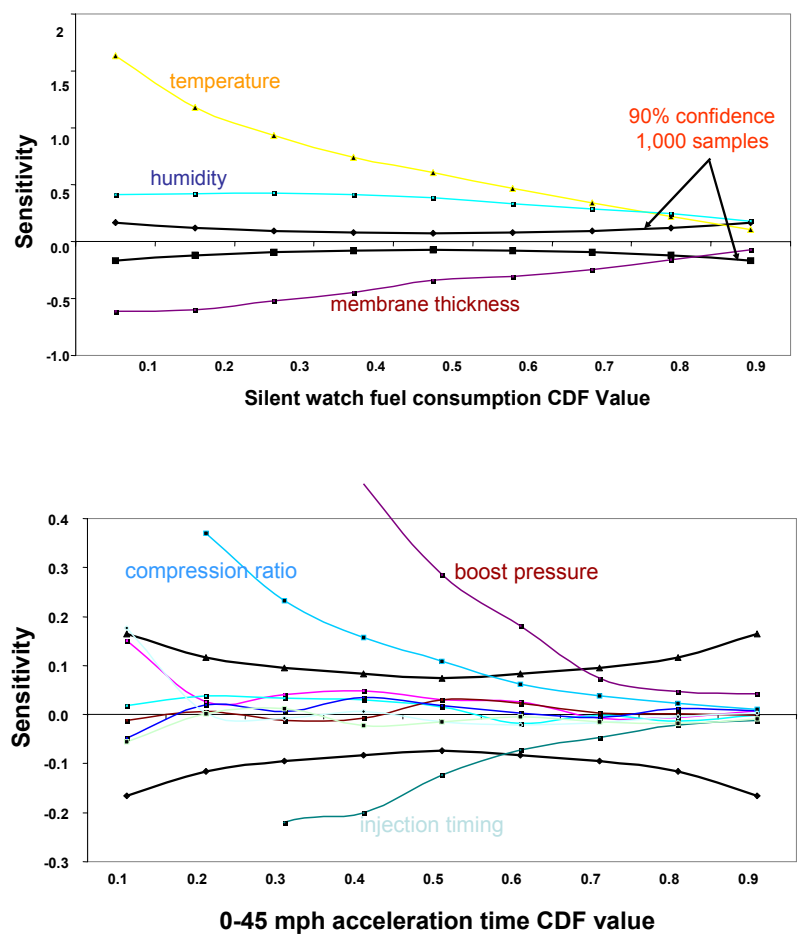

Figure 8: CDF sensitivity examples

The plot on the top indicates that all three fuel cell random parameters are statistically significant to almost the entire CDF range of the silent watch fuel consumption. The plot at the bottom indicates that only boost pressure, compression ratio, and injection timing are statistically significant to the largest part of the CDF range of the acceleration performance.

Using this type of sensitivity analysis, we were able to identify the most important random parameters and decrease the size of the optimization under uncertainty problem significantly. The results are summarized in Table 5 according to output of interest.

Table 5: Statistically significant random parameters for the three different outputs of interest

\begin{tabular}{|c|c|c|}
\hline $\begin{array}{c}\text { Driving cycle fuel } \\
\text { economy }\end{array}$ & $\begin{array}{c}\text { Acceleration } \\
\text { performance }\end{array}$ & $\begin{array}{c}\text { Silent watch fuel } \\
\text { consumption }\end{array}$ \\
\hline Injection timing & Injection timing & Temperature \\
\hline Frontal area & Frontal area & Humidity ratio \\
\hline Rolling resistance & Boost pressure & Membrane thickness \\
\hline $\begin{array}{c}\text { Transmission } \\
\text { efficiencies }\end{array}$ & $\begin{array}{c}\text { Transmission } \\
\text { efficiencies }\end{array}$ & \\
\hline & Compression ratio & \\
\hline
\end{tabular}

\section{SURROGATE MODELING}

After having identified the most important parameters and decreased the dimensionality of the problem we sampled the design space and created surrogate models for use in the optimization under uncertainty process.

We used the optimal symmetric Latin hypercube (OSLH) sampling technique to sample the design space. It is an efficient space-filling sampling method for constructing high-quality metamodels with very few samples [19]. We then adopted a local polynomial fitting technique, using the cross-validated moving least squares (CVMLS) method, to create the surrogate models of the highfidelity simulation models [20].

\section{RELIABILITY-BASED DESIGN OPTIMIZATION}

Optimization is concerned with achieving the best outcome of a given objective while satisfying certain restrictions. It has been observed that the deterministic optimum design does not necessarily have high reliability. To ensure that the optimum design is also reliable, the optimization formulation must include reliability constraints.

Classical reliability-based design optimization (RBDO) methods follow the so-called double-loop approach. It employs two nested optimization loops; the design optimization loop (outer) and the reliability assessment loop (inner). The latter is needed for the evaluation of each probabilistic constraint. There are two different methods for the reliability assessment; the Reliability Index Approach (RIA) [21] and the Performance Measure Approach (PMA) [22, 23]. Although either approach can be used, PMA is in general more efficient, especially for high-reliability problems [23].

The double-loop RBDO formulation is usually computationally inefficient due to the nested optimization loops. For this reason, two new classes of RBDO 
formulations have been recently proposed. The first class decouples the RBDO process into a sequence of a deterministic design optimization followed by a set of reliability assessment loops [24, 25]. The series of deterministic and reliability loops is repeated until convergence. The second class of RBDO methods converts the problem into an equivalent, single-loop deterministic optimization [26], leading therefore, to significant efficiency improvements.

The RBDO problem in this study is expressed as

\section{maximize fuel economy}

with respect to random engine design variables

given random vehicle and engine design parameters

such that the reliability of satisfying the performance constraints is greater than some threshold value

This problem can be solved using any appropriate RBDO method to yield optimal design that corresponds to a certain reliability level specified by the designer. Here we use a recently developed, highly efficient single-loop RBDO method [26]. Recall that reliability $R$ is defined as

$$
R=1-P_{f},
$$

where $P_{f}$ is probability of failure. In other words, we demand that the probability of violating a performance constraint (due to the uncertainties) is less than a specified threshold value.

In our RBDO problem we have 4 random design variables (the engine design variables) and 4 random parameters. We use the means of the random variables as optimization variables of the problem and assume constant standard deviations. Also, we use the optimal values obtained previously using deterministic optimization for the hydraulic system quantities. The distribution types and ranges of the design variables and parameters are listed in Tables 6 and 7, respectively.

Table 6: Random design variables of the RBDO problem

\begin{tabular}{|l|c|c|c|}
\hline \multicolumn{1}{|c|}{ Random variable } & $\begin{array}{c}\text { Lower } \\
\text { bound }\end{array}$ & $\begin{array}{c}\text { Upper } \\
\text { bound }\end{array}$ & $\begin{array}{c}\text { Distribution } \\
\text { information }\end{array}$ \\
\hline Displacement [L] & 6 & 9 & $\mathrm{~N}(\mu, 0.025)$ \\
\hline Compression ratio [-] & 12 & 17 & $\mathrm{~N}(\mu, 0.1)$ \\
\hline Boost pressure [bar] & 1.87 & 2.55 & $\mathrm{~N}(\mu, 0.1)$ \\
\hline $\begin{array}{l}\text { Wastegate activation } \\
\text { speed [RPM] }\end{array}$ & 1000 & 1600 & $\mathrm{~N}(\mu, 50)$ \\
\hline
\end{tabular}

Table 7: Random parameters of the RBDO problem

\begin{tabular}{|l|c|}
\hline \multicolumn{1}{|c|}{ Random parameter } & Distribution information \\
\hline Injection timing [ ${ }^{\circ}$ ATDC] & $\mathrm{N}(350,1)$ \\
\hline Frontal area [m2] & $\mathrm{N}(7.5,0.75)$ \\
\hline
\end{tabular}

\begin{tabular}{|l|c|}
\hline Transmission efficiencies [-] & $\mathrm{N}(0.94,0.02)$ \\
\hline $\begin{array}{l}\text { Differential and rolling resistance } \\
\text { scaling parameters [-] }\end{array}$ & $\mathrm{N}(1,0.1)$ \\
\hline
\end{tabular}

\section{PERFORMANCE RELIABILITY ASSESSMENT}

The RBDO problem is solved for several reliability levels for satisfying the performance constraints to quantify tradeoffs with fuel economy. Table 8 summarizes the results.

Table 8: Fuel economy and engine design for different reliability levels

\begin{tabular}{|c|c|c|c|c|c|c|c|}
\hline Reliability [\%] & 93.3 & 96.4 & 98.2 & 99.3 & 99.7 & 99.8 & 99.9 \\
\hline Fuel economy [mpg] & 6.69 & 6.62 & 6.54 & 6.44 & 6.35 & 6.29 & 6.18 \\
\hline Displacement [L] & 6.5 & 6.8 & 7.1 & 7.6 & 7.9 & 8.2 & 8.7 \\
\hline Compression ratio [-] & 16.85 & 16.82 & 16.79 & 16.75 & 16.72 & 16.70 & 16.67 \\
\hline \begin{tabular}{c} 
Boost pressure [bar] \\
\hline $\begin{array}{c}\text { Wastegate activation } \\
\text { speed [RPM] }\end{array}$
\end{tabular} 12.40 & 2.37 & 2.34 & 2.30 & 2.27 & 2.25 & 2.22 \\
\hline
\end{tabular}

It can be seen that the engine size increases, while compression ratio, and boost pressure decrease with increasing level of desired reliability of performance, which is, of course, detrimental to fuel economy. Looking at the two extremes of the obtained Pareto set (see Figure 9), we can observe that an improvement of $6.6 \%$ performance reliability (from $93.3 \%$ to $99.9 \%$ ) induces a $7.6 \%$ fuel economy reduction (from $6.69 \mathrm{mpg}$ to 6.18 $\mathrm{mpg}$ ). It can also be seen that the Pareto curve is highly nonlinear: we must sacrifice slightly less optimality to improve performance reliability from $93.3 \%$ to $99.3 \%$ than from $99.3 \%$ to $99.9 \%$.

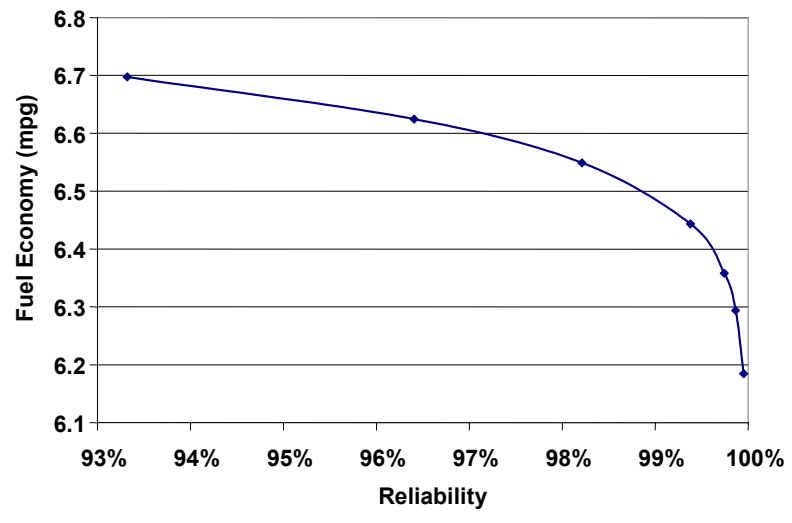

Figure 9: Quantification of tradeoffs between fuel economy and performance reliability 


\section{SUMMARY AND CONCLUDING REMARKS}

In this article we first obtained a deterministic optimal design of a hydraulic-hybrid powertrain to maximize fuel economy of a medium dual-use truck with a fuel cell APU subject to performance constraints. Realizing that the optimal design may be unreliable due to uncertainties not taken into account in the modeling and optimization processes, we then proceeded with identifying uncertainties in the engine, fuel cell, driveline and vehicle design or operating parameters, and determining their statistical significance. Finally, we performed a reliability-based design optimization parametric study to quantify the tradeoffs between maximizing fuel economy and reliability of satisfying performance constraints.

The major conclusions drawn are the following:

- Taking uncertainties into account has a great impact on design decisions. Different optimal engine designs for the hydraulic-hybrid powertrain of this case study are obtained for different reliability targets.

- The parametric reliability-based design optimization study showed that a substantial amount of optimality (i.e., fuel efficiency) must be sacrificed to increase the reliability of satisfying performance constraints.

- The optimality vs. reliability trade-off in our example is highly nonlinear. The amount of optimality that needs to be sacrificed as we approach very high reliability levels increases in an exponential fashion.

- Expert opinion should be sought to identify and quantify all sources of uncertainty. The number of uncertainties can be as large as necessary since moderate size Monte Carlo simulations can be used to perform sensitivity analysis on the results, determine the statistically significant uncertainties, and decrease the problem size.

\section{ACKNOWLEDGMENTS}

The authors would like to thank Ms. Denise McKay, and Dr. Jay Pukrushpan for their help with the fuel cell model and for providing useful experimental data, Mr. Burit Kittirungsi and Mr. Byungchan Lee for their help with the VESIM model, and Mr. Ashish Aleti, Mr. James Allison, Ms. Jinghong Liang, and Mr. Erik Rask for executing the simulations and generating the optimization results. Finally, the authors would like to express their appreciation for the technical and financial support of the Automotive Research Center (ARC), a U.S. Army RDECOM Center of Excellence for Modeling and Simulation of Ground Vehicles led by the University of Michigan.

\section{REFERENCES}

1. B. Wu, C.-C. Lin, Z. Filipi, H. Peng, and D. Assanis, "Optimal Power Management for a Hydraulic Hybrid Delivery Truck", Journal of Vehicle System Dynamics, 42(1-2):23-40, 2004.

2. Z.S. Filipi, L.S. Louca, B. Daran, C.-C. Lin, U. Yildir, B. Wu, M. Kokkolaras, D.N.Assanis, H. Peng, P.Y. Papalambros, and J.L. Stein, "Combined optimization of design and power Management of the hydraulic hybrid propulsion system for a $6 \times 6$ medium truck," International Journal of Heavy Vehicle Systems, 11(3-4):371-401, 2004.

3. H.H. Dobbs, E.T. Kallio, and J.M. Pechacek, "U.S. Army Strategy for Utilizing Fuel Cells as Auxiliary Power Units," SAE paper 2001-01-2792.

4. M. Venturi, and A. Martin, "Liquid-fueled APU fuel cell system for truck application," SAE paper 200101-2716.

5. M. Venturi, E. Kallio, S. Smith, J. Baker, and P. Dhand, "Recent results on liquid-fuelled APU for truck application," SAE paper 2003-01-0266.

6. J. Zizelman, J. Botti, J. Tachtler, and W. Strobl, "Solid oxide fuel cell auxiliary power unit - A paradigm shift in electric supply for transportation," SAE paper 2000-01-C070.

7. C.J. Brodrick, M. Farshchi, H.A. Dwyer, S.W. Gouse, J. Martin, and M. Von Mayenburg, "Demonstration of a proton exchange membrane fuel cell as an auxiliary power source for heavy trucks," SAE paper 2000-01-3488.

8. Z. Filipi, L. Louca, A. Stefanopoulou, J. Pukrushpan, B. Kittirungsi, and H. Peng, "Fuel cell APU for silent watch and mild electrification of a medium tactical truck," SAE paper 2004-01-1477.

9. L.S. Louca, and U.B. Yildir, "Modeling and Reduction Techniques for Studies of Integrated Hybrid Vehicle Systems," Proceedings of the 4th International Symposium on Mathematical Modeling, Vienna, Austria, published in the series ARGESIMReports, ISBN 3-901608-24-9, Vienna, Austria, 2003.

10. D.N. Assanis, Z.S. Filipi, S. Gravante, D. Grohnke, X. Gui, L.S. Louca, G.D. Rideout, J.L. Stein, Y. Wang $Y$, "Validation and Use of SIMULINK Integrated, High Fidelity, Engine-In-Vehicle Simulation of the International Class VI Truck," SAE Paper 2000-01-0288.

11. L.S. Louca, J.L. Stein, and D.G. Rideout, "Integrated Proper Vehicle Modeling and Simulation Using a Bond Graph Formulation," Proceedings of the 2001 International Conference on Bond Graph Modeling, Vol. 33, No. 1, pp. 339-345, Phoenix, AZ, published by the Society for Computer Simulation, ISBN 156555-221-0, San Diego, CA.

12. D.N. Assanis and J. Heywood, "Development and use of a computer simulation of the turbo compounded diesel system for engine performance 
and component heat transfer studies," SAE Paper No. 86-0329.

13. G.J. Delagrammatikas, A Design Optimization Methodology for Advanced and Hybrid, DieselBased, Automotive Powertrains, PhD thesis, University of Michigan, 2001.

14. G.J. Delagrammatikas and D.N. Assanis, "The reverse engineering of a turbocharged diesel engine through a unified systems approach," SAE Paper No. 01-1244.

15. D.R. Jones, "The DIRECT Global Optimization Algorithm'," Encyclopedia of Optimization, 1:431440, Kluwer, 2001.

16. T. Coleman, M.A. Branch, and A. Grace, Optimization Toolbox for Use with MATLAB, User's Guide, The MathWorks, Inc., Natick, MA, 1999.

17. J.T. Pukrushpan, A.G. Stefanopoulou, and H. Peng, Control of Fuel Cell Power Systems, Springer, 2004.

18. S. Mohanty and Y.T. Wu, "CDF sensitivity analysis technique for ranking influential parameters in the performance assessment of the proposed high-level waste repository at Yucca Mountain, Nevada, USA," Reliability Engineering and System Safety, 73:167176, 2001.

19. K.Q. Ye, W. Li, and A. Sudjianto, "Algorithmic construction of optimal symmetric Latin hypercube designs," Journal of Statistical Planning and Inference, 90:145-159, 2000.

20. J. Tu, "Cross-validated multivariate metamodeling methods for physics-based computer simulations,"
In Proceedings of the IMAC-XXI: A Conference and Exposition on Structural Dynamics, Orlando, Florida, 2003.

21. J. O. Lee, Y.O. Yang, and W.S. Ruy, "A Comparative Study on Reliability Index and Target Performance Based Probabilistic Structural Design Optimization," Computers and Structures, 80, 257269, 2002.

22. J. Tu, K.K. Choi, and Y.H. Park, "A New Study on Reliability-Based Design Optimization," ASME Journal of Mechanical Design, 121, 557-564, 1999.

23. B.D. Youn, K.K. Choi, and Y.H. Park, "Hybrid Analysis Method for Reliability-Based Design Optimization," ASME Journal of Mechanical Design, 125(2), 221-232, 2003.

24. X. Du and W. Chen, "Sequential Optimization and Reliability Assessment Method for Efficient Probabilistic Design," ASME Journal of Mechanical Design, 126(2), 225-233, 2004.

25. J.O. Royset, A. Der Kiureghian, and E. Polak, "Reliability-based optimal structural design by the decoupling approach," Reliability Engineering \& System Safety, 73, 213-221, 2001.

26. J. Liang, Z.P. Mourelatos, and J. Tu, "A single-loop method for reliability-based design optimization," Proceedings of the 30th ASME Design Automation Conference, Salt Lake City, Utah, Paper no. DETC2004/DAC-57255, 2004. 